\title{
LITHIUM-ASSOCIATED HYPERPARATHYROIDISM:
}

\section{A CASE REPORT}

Yuksel Altuntas, Feyza Yener Ozturk, M. Serdar Yıldız

Sisli Etfal Training and Research Hospital

Department of Endocrinology and Metabolism, Istanbul-TURKEY

\section{INTRODUCTION}

Lithium carbonate therapy has continued to be a mainstay treatment for bipolar disease and schizoaffective disorders. Hypercalcemia and hyperparathyroidism (HPT) is an underappreciated, but relatively common occurence, with a prevalence ranging from 6,3 to $50 \%$ in patients requiring long-term lithium therapy. It is still unclear whether lithium initiates HPT or promotes an underlying subclinical state. Lithium antagonizes the calcium-sensing receptor (CASR) resulting in an increase in the threshold level of calcium required for suppression of serum PTH. This is validated by the fact that many patients with lithium associated hyperparathyroidism (LAH) have inappropriately low-normal urinary calcium excretion. LAH reflects a spectrum of disease from single to multigland involvement with a variable responce of each parathyroid gland to the continous PTH stimulation.

\section{CASE REPORT}

A 52 year old female with bipolar disorder who had been treated with 900 mg lithium per day for two years, was referred to our endocrine outpatient clinic for evaluation of hypercalcemia. She denied having any symptoms related to hypercalcemia. Her blood and urine tests were shown in Table-1.

Table-1: Laboratory results of the patient.

\begin{tabular}{|l|c|}
\hline Calcium (range:8,6-10,2 mg/dl) & $10,9 \mathrm{mg} / \mathrm{dl}$ \\
\hline Phosphorus (range:2,6-4,5 mg/dl) & $3,4 \mathrm{mg} / \mathrm{dl}$ \\
\hline Creatinine (range:0-0,95 mg/dl) & $0,8 \mathrm{mg} / \mathrm{dl}$ \\
\hline PTH (range:15-65 pg/ml) & $191 \mathrm{pg} / \mathrm{ml}$ \\
\hline 24-hr urinary calcium (range:100-321mg/dl) & $66 \mathrm{mg} / \mathrm{day}$ \\
\hline
\end{tabular}

Her bone mineral densitometry showed reduced T-score:-2 (neck of femur), -1,3 (spine). Parathyroid scintigraphy with Tc-99m MIBI showed a parathyroid pathology with an isotope retention at lower pole of left thyroid gland (Figure-1).

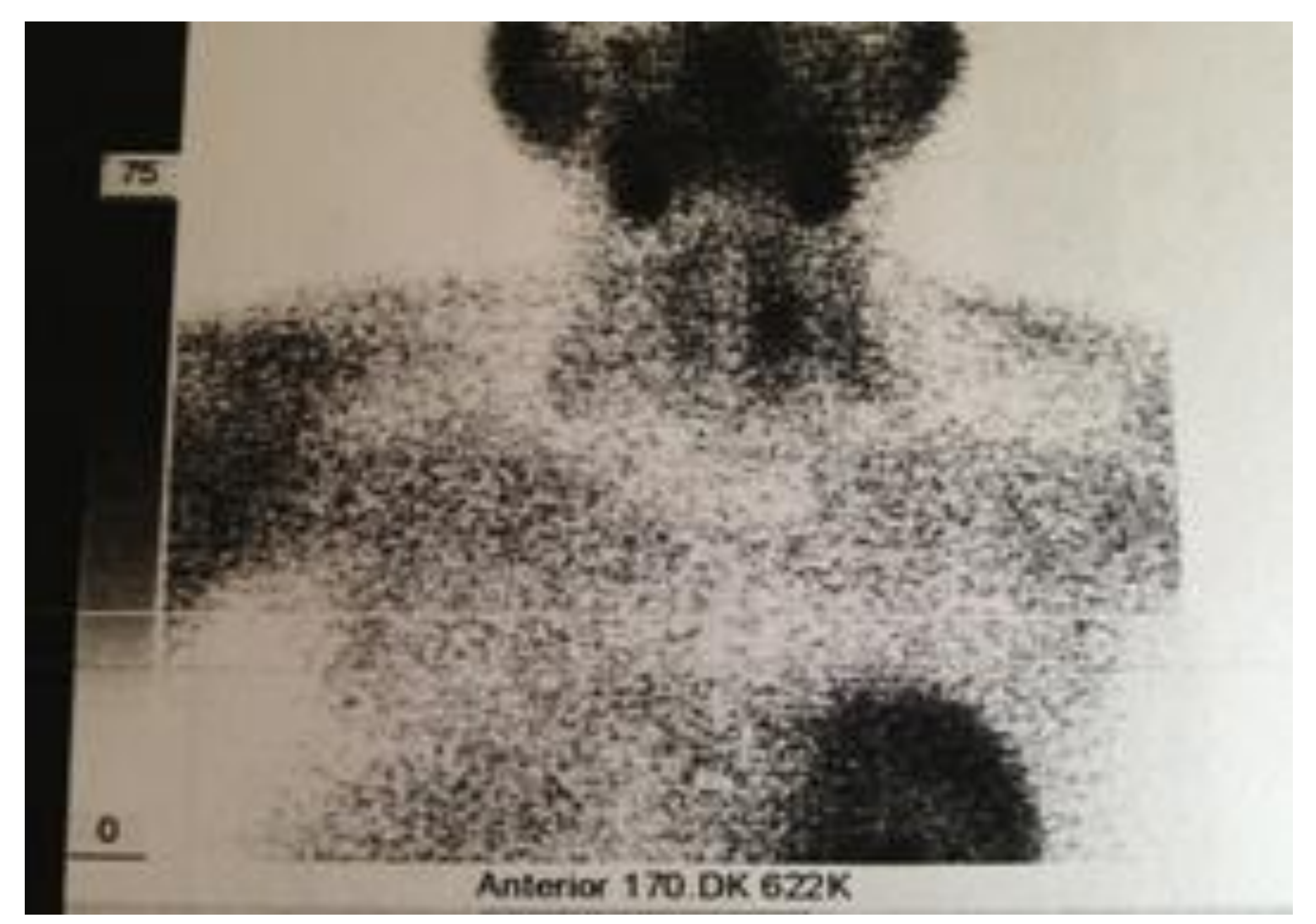

Figure-1: Tc-99m parathyroid scintigraphy visualizes isotope retention at the lower pole of left thyroid gland.

She was diagnosed as lithium associated hyperparathyroidism. After consultation with her psychiatrist, lithium therapy was stopped. After 2 weeks of cessation of lithium therapy, her serum calcium decreased to $10,1 \mathrm{mg} / \mathrm{dl}$. As she didn't meet the criteria for parathyroid surgery of asymptomatic hyperparathyroidism, a conservative approach to therapy was thought to be appropriate.

\section{CONCLUSION}

Approximately $10-15 \%$ of lithium treated patients become hypercalcemic with findings suggestive of hyperparathyroidism. By routinely monitoring serum calcium levels and long-term follow-up, healthcare providers can reduce the morbidity and improve the quality of life. 